\title{
Practical Reasonableness: Some Metaethical Issues
}

\author{
Evan Simpson
}

Published online: 24 July 2013

(C) The Author(s) 2013. This article is published with open access at Springerlink.com

This essay develops James Lenman's view that "moral inquiry is politics." ${ }^{11}$ Unlike empirical investigation, moral inquiry is not connected with a domain of facts that exist independently of the inquiry and help explain its success. It is outward looking - your thought that slavery is wrong is not a thought about you - but confident moral beliefs are not best understood as receptivity to moral aspects of the world. Rather, they come from successfully negotiating, constructing and sustaining the rules of a moral community. Lenman's picture entails an expressivist approach to moral philosophy in contrast to moral realism, but it also exhibits cognitively ample forms of approval and disapproval that expressivists have not very fully explored.

In order to frame the cognitive richness of practical deliberation, the first part of this discussion sets out important metaethical parameters. In particular it surveys differences between semantic and epistemic conceptions of truth in connection with determining and justifying reasons for belief. They suggest a case for saying that when philosophers speak of normative truth they can only demonstrate reasonableness. The second part of the discussion supports this case by displaying the advantages of focussing upon reasonableness. It supports locating a cognitivist expressivism between the extremes of normative realism and non-cognitivism where the weaknesses of standard expressivism can be avoided. The benefits include better understanding and potentially addressing many of the ethical and political issues that arise in morally engaged societies. Practical inquiry is inherently subject to disputes that go unsettled, making it dubious that "We may, and must, assume our opinion to be true for the guidance of our own conduct." ${ }^{\text {"2 }}$ By preferring to make

\footnotetext{
1 James Lenman, "What Is Moral Inquiry?," Proceedings of the Aristotelian Society Supplementary Volume 81, 2007, p. 76.

2 John Stuart Mill, On Liberty, ed. A. Castell (Northbrook, IL, 1947), p. 19.
}

E. Simpson $(\square)$

Department of Philosophy, Memorial University of Newfoundland, St. John's, NL, Canada e-mail: esimpson@mun.ca 
reasonable choices instead of seeking truth for purposes of action we can move beyond sectarian divisions to a kind of moral collaboration.

\section{Truth and Reasonableness}

Following Lenman, let us call normative beliefs "intuitions" in broad contrast to beliefs that arise from factual observation. These observational beliefs define terrain on which truth is indispensable for sound practical reasoning. True beliefs about means to ends anchor the conceptual framework of instrumental rationality and deliberations leading to effective social policy and personal success. In this respect the truth is essential for reasoning in which an agent formulates plans and makes decisions, but these practical concerns contrast with normatively ambitious extensions of truth that go beyond the clear results of observation to the ideals and aspirations that explain the value placed upon public and private objectives. The resistance of such normative matters to factual demonstration is typical of moral and political intuition, making it difficult to speak convincingly about normative knowledge of them.

Most of the relevant properties of intuition are well illustrated by our emotional responses to things, such as fear of conflict or hopes for reform. "Emotivism" was a brand name for 20th Century non-cognitivists, but cognition is complex. It encompasses both the sentient behavior in animals that negotiate their surroundings intelligently and the sapient actions of human beings who respond rationally to their environment. Sentience is the biological phenomenon that distinguishes conscious awareness from the responses of thermostats. Sapience is the quality characteristic of rational animals that display grasp of propositional content and inference. ${ }^{3}$ Emotional thinking is neither simply sentient nor ideally rational, marking ground between these modes of awareness that should be open to explication by a form of cognitivist emotivism or expressivism. This ground, we may expect, will not display a sharp division between beliefs and other mental states that should fit the world and those, such as desires, that we are motivated to make the world fit. ${ }^{4}$ In order to be tenable, in other words, expressivism will have to reject a dichotomy between cognitive and conative states.

If this dichotomy is rejected it seems best to construe "belief" not as the name of a distinct psychological state but as a generic term for keeping track of commitments within a discourse. ${ }^{5}$ These commitments include logical sensitivity to patterns of valid inference, but "belief" is a broad term of art that covers mental pictures and emotional responses as well as propositional attitudes. So understood, in feeling fear one believes oneself endangered even if one also believes that there is no serious chance of harm. Such awkward intuitions lead some to speak in other

\footnotetext{
${ }^{3}$ Robert B. Brandom, Making It Explicit: Reasoning, Representing, and Discursive Commitment (Cambridge, MA: Harvard University Press, 1994), pp. 4-6.

4 This point is critically developed by Bennett W. Helm, Love, Friendship, and the Self (Oxford: Oxford University Press, 2009), pp. 7 and 55-56.

5 This characterization follows Neil Sinclair, "Propositional Clothing and Belief," The Philosophical Quarterly, vol. 57, no. 228, 2007, p. 253.
} 
ways, ${ }^{6}$ but there is no contradiction here: it is perfectly possible to believe oneself in danger while realizing that one's fear is unfounded in that it lacks the normal determining reasons for the emotion. Speaking of beliefs has the benefit of calling attention to the fact that there are deliberative resources for dealing with the awkward emotional commitment, leading the inappropriate feeling to be addressed by recognition that no real harm threatens. "Belief" marks the difference between considered intuitions and recalcitrant illusions, intuitions being less independent from higher cognitive processes than the persistent Müller-Lyer illusion, for example. To be sure, it takes time and effort to train oneself out of a phobic belief. Practical deliberation may remain indecisive, leaving conflicts within as well as between individuals, but this is a constitutional liability of agents who are intuitive as well as rational beings.

The psychological latitude of beliefs can also be usefully illustrated by our thinking about the various institutional proprieties that give people a place in the conventional realities that shape orderly social relationships. Thus, people count as spouses under established procedures of marriage that confer certain rights and obligations upon two partners. These institutional realities are usually very fact-like, providing clear objects of true belief. Sometimes, however, moral and political issues arise that call the desirability of particular institutions into question. When exclusively heterosexual marriage became contested, beliefs about spouses began to display a desire-like dimension not previously so apparent. Of course, one might insist that the distinction between beliefs and desires remains perfectly clear. There are beliefs about spouses: for example, only relationships between men and women count as marriages. And there are desires: for example, one wishes that there be institutional change, or that there not be. However, explicating the belief about spousal relationships requires an account of who is doing the counting. The institutional fact comes to something like this: let us only count relationships between men and women as marriages. Such counting-as is an act of volition. It is already the expression of desire, and where desires conflict the facts become open to negotiation.

As the hard facts of the matter become correspondingly less evident in such cases, two contrasting conceptual options suggest themselves. One is chosen by Joshua Cohen, who pursues an expansive role for truth: The "political truth" of hopes and ideals cannot be put aside "while preserving notions of belief, assertion, judgment, reason and objectivity, all of which are essential to an idea of public reason." Moral and political claims "must be truth-apt ... if there is to be a common ground of argument under conditions of doctrinal disagreement." 7 These imperatives are not obviously valid, however, if some reasoning is a matter of emotional reasonableness, for which there need not be a truth to be discovered or a proposition to be proved. It is enough for reasonableness that moral and political beliefs are

\footnotetext{
${ }^{6}$ E.g., Allan Gibbard, Wise Choices, Apt Feelings (Oxford: Clarendon Press, 1992), pp. 39-40; and Justin D'Arms and Daniel Jacobson, "The Significance of Recalcitrant Emotion (or Anti-quasijudgmentalism)," in Anthony Hatzimoysis, ed., Philosophy and the Emotions (Cambridge: Cambridge University Press, 2003), pp. 127-145.

7 Joshua Cohen, "Truth and Public Reason," Philosophy \& Public Affairs, vol. 37, no. 1, 2009, pp. 5 and 17.
} 
supported by thoughtful deliberation. ${ }^{8}$ One's positions should not be reached arbitrarily but include concern for reasoning even if they express intuitions whose justifying reasons defy full factual demonstration. Pursuing this option will promote a narrow role for truth by displaying reasonableness as a distinctive virtue of practical reasoning that is capable of accommodating argument, assertion, judgment, etc.

The other option for truth is to multiply its role rather than to expand it. This suggestion emerges naturally from Eugene Garver's point that to be part of a moral community is to have one's stories heard. To think of these accounts only as forms of self-expression rather than statements of truth, he maintains, would fail to take them seriously enough. The better alternative is to accept "multiple truths" or "a diversity of truths," corresponding to incommensurable personal and communal narratives. ${ }^{9}$ Although there is much appealing in this idea, it describes reasonableness better than it describes truth. Reasonableness is plural. We recognize that there may be a variety of reasonable opinions about many matters, especially in the ambiguous situations of emotional conflict and moral difficulty that novelists and playwrights help us understand. Truth, by contrast, is singular. The truth about something is like the most reasonable position concerning it and may prove to be an unobtainable ideal as we assert and argue in defence of our different reasonable judgments. In the case of emotional intuitions that ideal may also prove illusory.

Classical emotivism was principally a theory about moral beliefs, but these beliefs have a more general form. Fear has already been offered as a simple model. Like other emotions fear has both determining and justifying reasons. Its determining reasons are the perceived properties that normally evoke the emotion, such as anticipated loss or injury. (The qualification, "normally," is necessary because of cases in which the perception of loss or injury is met impassively or even joyously: determining reasons are defeasible.) The typical conditions of determining reasons are descriptive properties: Loss and injury are verifiable facts when they occur. They stand in contrast to the justifying properties that make things not only feared but fearful. These things are dangers. They are inherently fear-worthy, but they are not verifiable in the same way. Whether a loss is worthy of fear can always be contested. As Martin Luther said of temporal threats, "Take they our life, goods, fame, child and wife ... they yet have nothing won." ${ }^{10}$ Whether these undoubted losses should be feared is a matter for deliberation because the determining reason for fear provides no conclusive answer. The possibility of coherently wondering whether bodily injury is worth fearing shows how people can reasonably differ about the things they identify as dangers and thus as to be feared. It is an otiose hypothesis that there is nevertheless a truth of the matter.

\footnotetext{
8 The point is nicely developed by David Enoch, "An Outline of an Argument for Robust Metanormative Realism," Oxford Studies in Metaethics, 2007, pp. 34-38, and by Bennett W. Helm, Emotional Reason: Deliberation, Motivation, and the Nature of Value (Cambridge: Cambridge University Press, 2001), pp. 200-201.

${ }^{9}$ Eugene Garver, For the Sake of Argument: Practical Reasoning, Character, and the Ethics of Belief (Chicago: University of Chicago Press, 2004), pp. 17-18.

${ }^{10}$ Martin Luther, "A Mighty Fortress." Compare Shakespeare's "Who Steals My Purse Steals Trash," Othello III, iii, 157.
} 
Developing this dual-reasons model and extending it to moral and political beliefs will show why aiming at the truth is appropriate for beliefs concerning the determining reasons of the relevant emotions, whereas aiming for reasonableness is appropriate for beliefs about their justifying reasons. Explicating the point will also display contrasts between reasonableness and rationality. Both are exercises of reasoned deliberation but reasonableness is more permissive, departing from "'Rational Uniqueness,' the view that there is a unique maximally epistemically rational response to any given evidential situation." ${ }^{11}$ Reasonableness does not decisively depend upon what can be known in the same way, since questions of emotion-worthiness may remain open when there is agreement on all the facts. The point leads to interesting and important questions about the nature of intuitions, one of which (the combination of desire-like and belief-like elements) is addressed in the next section. A prior task is to set out more fully how reasonableness is amenable to a cognitivist expressivism that lies between robust moral realism and non-cognitivism.

Robust moral realism holds that moral beliefs are epistemically truth-apt. The common feature of this family of theories is that one can seriously quest after moral knowledge, expecting the truth to sometimes be obtainable. ${ }^{12}$ Realism in this sense is distinct from "error theory," which accepts the idea of moral beliefs as truth-apt but regards them as uniformly false. It is also distinct from theories that postulate moral truths but do not require them to be discoverable. A special case of the latter kind is the family of views that regard normative beliefs as semantically truth-apt in contrast to making epistemic claims. This distinction is explained further below, but it will be useful first to contrast non-realistic cognitivism with non-cognitivism, the latter consisting of three related views: Moral judgments of the form " $\mathrm{X}$ is wrong" or "X is good" express attitudes of approval or disapproval towards their subjects; moral terms have a different sort of meaning from the descriptive terms used to state ordinary matters of fact, such as the truth that grass is green; and moral claims lack truth conditions. ${ }^{13}$

Non-cognitivism is aptly named, since there is no clear room for the reasonableness of moral claims here. If the disapproval conveyed by "Slavery is wrong," for example, were an expression of mere disapproval no scope would be available for deliberation. Typically, though, the sentence does not express simple disapproval. Rather, it reflects a view of slavery as warranting moral hatred or indignation in virtue of various facts of human trafficking. However, hating slavery for these determining reasons does not yet show it to be morally offensive. That comes with the further perception that hatred or righteous indignation is justified by violations of human equality or dignity. The justifying reason identifies slavery as worthy of disapproval on explicitly moral grounds. A natural gloss on sentences

\footnotetext{
11 David Christensen, "Epistemology of Disagreement: The Good News," Philosophical Review, vol. 116, no. 2, 2007, p. 210.

12 Some expressivists, such as Blackburn and Gibbard, also postulate moral knowledge. This idea is critically discussed in a companion to the present article: Cf. Evan Simpson, "Practical Reasonableness: Some Epistemic Issues," The Journal of Value Inquiry. doi:10.1007/s10790-013-9367-z.

13 This is Mark Schroeder's summary, "Expression for Expressivists," Philosophy and Phenomenological Research, vol. 76, no. 1, 2008.
} 
such as "Slavery is wrong" thus displays typical moral judgments as content-rich states of mind aroused by ascertainable facts and justified by reasons to protest toleration of those facts. Of course, because determining reasons for indignant disapproval do not logically justify the normative assessment, it is still possible to construe justifying reasons non-cognitively as expressions of desire-like states. The plausibility of understanding them in this way will be undermined, however, as intuitions display their capacity to be influenced by argument. They are much more redolent of judgment than non-cognitivist views typically recognize. Even if the first defining condition of these views is correct as far as it goes, it omits much of philosophical interest.

The distinction between determining and justifying reasons also bears upon the limitations of the second and third conditions of non-cognitivism. One might speak of the descriptive meaning of determining reasons and the evaluative meaning of justifying reasons, but the distinction between kinds of meaning does no clear work that is not already done by the distinction between kinds of reasons. On the one hand we have factual statements with which any rational person can ultimately be expected to agree. On the other hand, we have our reasons for hating something even though what makes something hateful (or whether it is hateful) is not a matter on which we can always gain agreement and responsibly claim knowledge. If considering slavery hateful is not justified by reference to a demonstrable reality, then differences of moral and political belief have to be managed through reasonable deliberation. It is this concept rather than meaning that requires further explication, and because that account will include the role of determining properties the third defining condition of non-cognitivism also has to be qualified. Our reasons for hating slavery and believing it hateful may depend upon believing it to be truly painful or injurious. Beliefs about the determining factors of our emotional responses do aim at truth. It is the reasonableness of differing justifying beliefs where there is no disagreement about the describable facts that needs more attention.

A serious issue about the reasonableness of justifying beliefs concerns the idea that truth or something like truth is a semantic virtue of normative claims. ${ }^{14}$ Although non-cognitivism excludes the truth of justifying reasons, many contemporary expressivists accept it as a consequence of the logical platitude that $p$ is true if and only if $p .{ }^{15}$ Any intelligible proposition is then semantically truth-apt, so that in reasonably assenting to "Slavery is wrong" one thereby accepts the truth of that sentence. In other words, any commitment to $p$ includes commitment to the truth of $p$, even if in only a minimal sense for which it has no further analysis or

\footnotetext{
${ }^{14}$ The qualification, "something like truth" may address discomfort in claiming truth for "slavery is wrong" by employing a word for ascriptive success that means "valid, or sound, or some such thing." See David Estlund, "The Insularity of the Reasonable: Why Political Liberalism Must Admit the Truth," Ethics, vol. 108, no. 2, 1998, p. 274. Jürgen Habermas similarly proposes an analogy between rightness and truth in Truth and Justification (Cambridge: Polity Press, 2003), pp. 270-271.

${ }^{15}$ E.g., Terry Horgan and Mark Timmons, "Cognitivist Expressivism," in Horgan and Timmons, eds., Metaethics After Moore (Oxford: Oxford University Press, 2006). They suggest that truth ascriptions to moral statements are "morally engaged semantic appraisals... in which semantic evaluation is 'fused' with moral evaluation" (p. 275). This metaphorical move should be unnecessary when one deploys the resources provided by reasonableness.
} 
metaphysical backing, such as correspondence to the facts. To say that a moral or political belief is true is therefore not to say that it is an object of knowledge, divorcing the semantic conception from epistemic issues. ${ }^{16}$ Hence, in many matters of practical interest, matters of justifying reasons in particular, striving to be reasonable need not be encumbered by metaphysical debate. It is one thing to recognize that deliberating about practical issues includes committing oneself "to there being reasons for one's positions." It is quite another thing to add, "and so to their normative truth." 17 Enoch makes this inference to the epistemic conception, thinking it essential for taking morality seriously, but this thought is superfluous as long as the reasonableness of justifying beliefs serves the same purpose.

It is also possible to avoid entanglement in the metaphysics of propositions. Moral beliefs can be conveyed in propositional clothing or propositional guise even if they are not taken as interestingly true. ${ }^{18}$ To be sure, "we call something a proposition when ... we apply the calculus of truth functions to it." 19 Noncognitivism therefore proposed a plethora of analyses of sentences outside this range, urging caution about assuming that thoughts expressed propositionally are always philosophically perspicuous. Various indicative sentences, including those of the sort "Slavery is wrong," might then be set outside any form of words to which the predicate "true" properly attaches. Nonetheless, declining the propositional gambit is unnecessary if Mark Schroeder's divorce of two roles for propositions succeeds. In one role, they are "the objects of attitudes like belief, desire, and assertion, and the bearers of truth and falsity." In the other, they "play a role in carving up the world at its joints, are associated with metaphysical commitment, and are the appropriate objects of excluded middle." ${ }^{20}$ Objects of the first sort do not entail a philosophically weighty commitment to the epistemic truth of moral and political beliefs - that is, to moral and political knowledge - again warranting stress upon reasonableness over truth.

Of course, the strategy of metaphysical avoidance will fail if the epistemic truth of our justifying reasons is particularly important to us. This would be the case if confident moral beliefs required people to not only "assert their commitments in an unqualified way" but also "insist on the correctness of such judgments for all." 21 However, the evidence is not very compelling for supposing that people do insist

\footnotetext{
${ }^{16}$ Whether a solely semantic conception of truth can be sustained is open to question because the shadow of metaphysical content is difficult to expunge entirely. James Dreier, "Meta-ethics and the Problem of Creeping Minimalism," Philosophical Perspectives, vol. 18, no. 1, 2004, provides an authoritative statement of the issue.

17 David Enoch, "Outline of an Argument for Robust Metanormative Realism,” p. 39 and p. 47, and Taking Morality Seriously: A Defense of Robust Realism (Oxford: Oxford University Press, 2011), p. 75.

18 The notion of propositional guises (including normative utterances as "secondary propositionalized transformations" of normative stances) is elaborated by Michael Pendlebury, "How to be a Normative Expressivist," Philosophy and Phenomenological Research, vol. 80, no. 1, 2010. Proposition-talk can also be considered an exercise in semantic pretense or make-believe. Cf. Bradley Armour-Garb and James A. Woodbridge, "The Story About Propositions," Noûs, vol. 46, no. 4, 2012.

19 Ludwig Wittgenstein, Philosophical Investigations (Oxford: Blackwell, 1953), section 135.

${ }^{20}$ Mark Schroeder, "Two Roles for Propositions: Cause for Divorce?," Noûs, vol. 47, no. 3, 2013, p. 410 .

21 Russ Shafer-Landau, Moral Realism: A Defence (Oxford: Clarendon Press, 2003), p. 32.
} 
upon something like truth and knowledge for their moral claims. It may well be that we begin as pre-theoretical realists, but that changes with learning. Although young children have not yet begun to differentiate between truth and reasonableness, the appearance of common-sense objectivity dissipates as they become deliberative agents, recognize the contestability of their intuitions, and begin to distinguish the determining from the justifying reasons for these judgments. ${ }^{22}$ To be sure, some philosophers pronounce the truth of their moral faith, but it is far from clear that such robust objective pretentions are part of the basic phenomenology of moral feelings or ordinary moral discourse. ${ }^{23}$ The aspirations and commitments of ordinary moral judgment need not extend beyond their reasonableness to their epistemic truth-aptness. In contrast to "Slavery is wrong," with which we expect reasonable people in a liberal society to concur, we may comprehensibly hesitate to say, "It is true that slavery is wrong" unless we wish to make an anodyne semantic point or recognize an example of special declarative language whose most famous example is, "We hold these truths to be self-evident, that all men are created equal...." 24 There is, in short, a prima facie case for supposing that distinctively moral and political deliberation and judgment insist less upon truth than upon reasonableness.

\section{Cognitivist Expressivism}

In order to develop this case, it will be useful to set out a challenge that it must ultimately satisfy. One can argue that when people make moral judgments and engage in moral disputes they express more than the reasonableness of their positions. After all, when people are confident in their moral opinions they normally view opposing positions as less well founded than their own. Sometimes this confidence amounts to thinking that the other positions are unreasonable, but in some cases people may regard the opposing views as just as reasonable as their own. In these cases, argument typically continues as people defend their views and try to show that the other side is somehow mistaken. Reasonableness, therefore, does not seem sufficient as a criterion of acceptable moral judgment.

Ultimately meeting this challenge will depend upon explicating the cognitive demands of continuing a morally significant conversation. This is an agenda that standard forms of expressivism are not well designed to satisfy. These theories represent normative claims as having a separate descriptive or non-normative component and a normative component. The descriptive component states the utterer's belief about a matter of fact, while the normative component records a desire-like attitude and supplies the motivational component typical of moral beliefs. Thus, "Slavery is wrong" indicates that there is something about slavery

\footnotetext{
22 Compare Shaun Nichols, Sentimental Rules: On the Natural Foundations of Moral Judgment (Oxford: Oxford University Press, 2004), pp. 166-98.

23 Simon Kirchen also argues generally that ethical phenomenology does not support any metaethical position over any other: "Ethical Phenomenology and Metaethics," Ethical Theory and Moral Practice, vol. 6, no. 3, 2003.

24 July 4, 1776, Declaration of the Congress of the USA.
} 
that one disapproves and is inclined to act against. Not everyone who makes this claim need disapprove of the same thing, so that determining the descriptive component of one's claim always deserves examination. It could turn out to be false, opening up room for rational disagreement. (Such factual errors have been important in discussions of ethnic intolerance, for example.) In all its standard versions, however, expressivism limits further argument by regarding the attitudinal component of intuitive judgment as simply a matter of desires or preferences rather than more interesting justifying reasons. An inkling of the resulting problem emerges from the possibility that in condemning slavery we may not only make different descriptive judgments but also express different disapproving attitudes. The practice arouses one person's hatred but another's indignation, say. The difference does not easily fit the model of mere preference, since the justifying reasons for hatred and indignation are different: hatred includes a perception of evils, whereas indignation includes a perceived violation of rights. Like competing descriptions, these reasons are subject to discussion and argument, making it difficult to accept expressivism until it accommodates their reasonableness.

Towards that end, suppose that human equality is called upon to justify extending certain liberties to everyone or promoting reformed patterns of income and wealth. At the same time, as part of avoiding the metaphysical entanglements of truths and propositions, consider the point non-propositionally. Rather than saying that freedoms and economic means should be similar because human beings are equal, the discussion of institutional reform may be considered "prepositionally": freedoms and means should be similar because of human equality. ${ }^{25}$ This modest regimentation of ordinary language assists in viewing human equality as an emotion-expressing rather than truth-representing concept: belief in equality is not a propositional attitude but commitment to a respectful picture of persons as persons. The device helps confirm that nothing requires bundling belief and reasonableness together with truth. Rather, one believes (propositionally) that $p$ if and only if one believes that $p$ is true, but one may believe prepositionally in something - such as human equality - without advancing this further belief. Although it is normally possible to dress an emotional belief in propositional clothing, expressing the belief prepositionally will prevent issues of truth from dominating discussions of reasonable political faith or moral conviction. Emotional belief resembles an intellectual stance, such as progressive preference for human equality over a conservative preference for recognizing personal distinctions. As such it can be reasonable as long as it hangs together with one's other commitments and is responsive to challenge. If asked, "You profess belief in human equality, so how can you justify your personal wealth?" a reasonable response could rest upon a set of life-choices - for example, to be generous to others - rather than upon a set of truths.

The prepositional rendering of stances and intuitions is consistent with the idea that emotional thinking is not strictly sapient or rational, but it leaves room for

\footnotetext{
25 Another version of the suggestion that non-propositional entities may be among the terms of the beliefrelation is offered by Ray Buchanan, "Is Belief a Propositional Attitude?," Philosophers' Imprint, vol. 12, no. 1, 2012.
} 
speaking of reasonableness in a way not easily accommodated within the desireplus-belief account of action favored by standard expressivism. On this account, rational agents search their propositional beliefs for those that identify the best means for satisfying their desires, but this picture does not well characterize the intuitions of emotional beings whose reasons exhibit no clear detachment between belief and desire. Rather, the fearful belief occasioned by a perceived threat is intimately linked to the fight-or-flight response. Such tendencies are built into emotional beliefs rather than resulting from desires distinct from them. ${ }^{26}$ As a result, emotionally reasonable agents do not simply adopt the means to their desires but seek to assure themselves that their desires are consonant with good justifying reasons. If the object feared lacks fear-worthiness, there is a good reason not to flee even if a true determining reason unreflectively prevails, leading to that action. In either event, the cognitive demands upon emotion keep the response open to deliberative review. Emotional beliefs thus have a place for standards of motivation by which the actions they occasion can be assessed separately from the satisfaction of desires. One may want to avoid injury, rightly believing flight to promise safety and act accordingly, but reasonably regret that rational action.

The cognitive demands of this picture are absent from expressivist theories that have no developed account of reasonable emotions. These theories do have clear virtues. By attaching normative judgments about slavery to descriptive beliefs about human trafficking, the judgments can display all the logical properties of descriptive propositions while exhibiting the action-guiding properties that these propositions by themselves lack. ${ }^{27}$ The theories correctly explain that different people may reject slavery for different reasons. They even explain how one who believes that slaves are property may not believe slavery to be wrong for want of disapproving the ownership of other human beings. Moreover, as Michael Ridge shows, these theories can bridge the gap between cognitivism and expressivism in one important respect: If cognitivism is the view that normative claims express beliefs rather than desires and expressivism is the view that normative claims express desires rather than beliefs, then an ecumenical expressivism can have the best of both worlds: normative claims express both beliefs and desires. ${ }^{28}$ However, it is easy to see that expressivist theories of this kind do not seriously renounce their non-cognitivism, subscribing uncritically to the assumptions of the belief-desire account of agency.

The cognitive limitations of Ridge's expressivism initially display themselves in the absence of a clear distinction between descriptive and determining properties. The basic account holds that an intuition of something's moral wrongness consists of a suitable state of disapproval for a certain descriptive property (or set of

\footnotetext{
${ }^{26}$ In this respect emotional beliefs are examples of the "besires" discussed (though not endorsed) by Michael Smith, The Moral Problem (Oxford: Blackwell, 1994), pp. 118-125. Generically, these beliefs exemplify what is called motivational internalism.

27 The fusion of semantic and moral evaluation suggested by Horgan and Timmons includes a version of this account. A comprehensive assessment of such approaches is given by Mark Schroeder in Being For: Evaluating the Semantic Program of Expressivism (Oxford: Oxford University Press, 2008) and subsequent articles.

${ }^{28}$ Michael Ridge, "Ecumenical Expressivism: The Best of Both Worlds?," Oxford Studies in Metaethics, vol. 2, 2007.
} 
properties) and a belief ascribing the property to that thing. Strictly construed, this makes disapproval too unmotivated. The characterization permits supposing that in believing slavery to be wrong one can hate it in virtue of any of its descriptive properties, such as lacking provision for vacations. The problem is that hating something should be done for relevant reasons. Just as one cannot normally fear rainbows but only things that presage harm, one cannot seriously despise slavery for arbitrary or insufficient reasons.

At first sight, this deficiency can be addressed through a minor revision. It is only necessary to restrict the relevant descriptive grounds of disapproval to the determining reasons for moral hatred, indignation, and the like. This qualification voids charges of arbitrariness by linking particular emotional responses to the properties that normally evoke them - causing other persons pain, for example. Although this is a small revision, however, it brings the deep weakness of noncognitivism to the surface. In fearing, hating or responding indignantly to anything the question appropriately arises whether the determining reasons render their object fearful, hateful or worthy of indignation. Expressivism is mostly silent about justifying reasons even in the "ideal advisor" version that Ridge prefers. ${ }^{29}$ Only referring to something like cruel pain or the indignity of servitude shows that slavery is reasonably disapproved because also reasonably deemed to be worthy of offense. A practice is hated for a determining reason, but its hatefulness depends upon a justifying reason for which expressivism makes no provision beyond supposing that justifying reasons are not belief-like but desire-like, resting ultimately upon preferences that resist examination.

Is this provision perhaps sufficient? The expressivist analysis has seemed especially plausible for "thick" concepts such as danger because their complex content can ostensibly be disentangled into separate descriptive and attitudinal components. Calling something a danger then reflects believing some unwanted loss to be in the offing. The concepts of virtues and vices are similarly viewed as sets of describable properties towards which there are typical desires and aversions. The appropriate response is that such characterizations fail because they neglect the justifying reasons for responses to describable things. The capacity for meaningful argument about attitudes towards the facts, in other words, shows that intuitions about them can be reasonable. Yet standard expressivism has a strong rejoinder to this response: To call an intuition reasonable is to say that one has a positive attitude towards the reasons for the belief. Reasonableness, therefore, does not reach fundamentally beyond the forms of reasoning that one prefers or desires. In other words, expressivism arguably precludes a cognitivist variant any stronger than Ridge's ecumenical hybrid for which normative claims express both beliefs about matters of describable fact and desires concerning those facts.

Lenman seems to concede the point in speaking of normative judgments as "a kind of desire" or "unwillingness ... to accept any rules for the regulation of my community that permit members of that community to murder, rape, torture and so on." In fact, his discussion warrants the cognitively richer (although still not "robust") reading that runs through his account.

$\overline{29}$ Ridge, "Ecumenical Expressivism," pp. 56-59. 
[W] deliberate together about what the terms of our moral community should be... It's an attempt by us to bring our - and not merely $m y$ - moral judgments into a harmonious state of reflective equilibrium... Moral inquiry is ... the attempt to arrive by co-deliberation at agreement on what might be an acceptable set of moral standards ... an attempt to determine what moral norms we might ... agree in endorsing ..., but where by "determine" I mean not so much discover as settle. ${ }^{30}$

This conclusion addresses the challenge posed above to cognitivist expressivism. Argument may continue, but trying to settle disputes is not principally a matter of correcting mistakes. It is a collaborative practice rather than an effort to demonstrate one position or refute another. Lenman shows here that there can be common grounds of agreement without requiring that one's claims be epistemically truth-apt. His mode of co-deliberation includes no commitment to normative truth, so that when philosophers speak of truth it is often only reasonableness that they can demonstrate.

The challenge then becomes demonstrating even this, or finding a distinctively cognitivist expressivism free from threats of regress. Expressivism generally recognizes that "What standards people accept is influenced by normative remuneration and normative discussion" but still represents the view as "noncognitivistic in the narrow sense that ... to call a thing rational is not to state a matter of fact, either truly or falsely." "31 A variant that glosses reasonableness in terms of thoughtful deliberation, sufficient reasons, and the like will in so doing refer to normative judgments that likewise lack factual determination and robust truth conditions. Reasonableness then arguably comes to an end in mere preferences for the arguments we favor. However, this reductive gambit can be resisted by stressing the importance of the fact that argument does not end. Politics goes on. The norms of association are challenged and renegotiated as circumstances offer reasons that test prevailing understandings. Standard expressivism recognizes that preferences are modified during the course of experience and discussion but encumbers itself unnecessarily by assuming that normative judgments and the preferences they display rest upon the desire side of a dichotomy. Keener attention to the ways in which all judgments can listen to reason should undermine the appeal of the question-begging distinction between desire-like and belief-like states.

Two features of the standards Lenman refers to are particularly significant for understanding emotional reasonableness as cognitively demanding. First, these standards are inherently objective in a clear sense. We are taught what to fear, whom to trust, when to show respect. Even infantile fears are quickly corrected by the standards of our communities. Second, there is also a clear sense in which these standards are not socially relative. They will usually reflect social norms and be generally accepted within a community but, like institutional facts, they are not finally authoritative because they can always be politically questioned and challenged. In disputing elements of public opinion one is often asking why one

\footnotetext{
${ }^{30}$ Lenman, "What is Moral Inquiry?," pp. 74-75.

31 Gibbard, Wise Choices, Apt Feelings, p. 264 and p. 8.
} 
should fear $\mathrm{X}$, trust $\mathrm{Y}$ or respect $\mathrm{Z}$. Judging these feelings to be warranted acknowledges well-defined norms of evidence but ones that are never finally established. On the one hand a coherent emotional life includes recognizing existing social norms of judgment, but on the other hand emotional maturity includes recognizing the contestability of the norms that make reasonable intuitions possible. Such maturity may not come easily outside pluralistic societies in which a multiplicity of reasonable standards is evident, but all cultures have prophets and critics whose example displays the variability of defensible norms. In contrast to the determining reasons and other descriptive beliefs whose truth is decided by the facts, there is no such definitive decision procedure for intuitions.

\section{Conclusion}

Yet it would be a mistake to hold that if nothing makes moral beliefs true then there is nothing other than one's own attitudes for evaluating competing views. Rather, when contests of emotional belief arise, discursive deliberation is called for in contrast to the accurate description that can resolve factual disagreements. Upon looking closely at practical argumentation, it becomes clear that reasonableness is a social capacity rather than an assessment of beliefs that fit the world. Ongoing social discourse can be frustrating because justifying reasons are contestable, but there is another way of saying this: Reasoning never comes to an end where we are left with mere preferences. Justifying reasons do not run out in a residue of non-cognitive attitudes remaining when all argument is over because reasonable discussion is inherently open to continuation.

Open Access This article is distributed under the terms of the Creative Commons Attribution License which permits any use, distribution, and reproduction in any medium, provided the original author(s) and the source are credited. 